\title{
Prediction of casing critical buckling during shale gas hydraulic fracturing.
}

MOHAMMED, A.I., OYENEYIN, B., BARTLETT, M., NJUGUNA, J. 


\title{
Prediction of casing critical buckling during shale gas hydraulic fracturing
}

\author{
Auwalu I Mohammed ${ }^{1}$, Babs Oyeneyin ${ }^{1}$, Mark Bartlett ${ }^{2}$ and James Njuguna ${ }^{1 *}$ \\ ${ }^{1}$ School of Engineering, Robert Gordon University, Garthdee Road, Aberdeen UK \\ ${ }^{2}$ School of Computing Science and Digital Media, Robert Gordon University, Garthdee Road, Aberdeen \\ UK \\ *Corresponding Author Email: j.njuguna@rgu.ac.uk; Tel.+44 (0) 1224262304
}

\begin{abstract}
Casing deformation during volume fracturing in shale gas horizontal wells is caused by both existing and induced stresses. These stresses jointly alter and compound the stress field around the casing leading to inefficient well stimulation as planned, lack of access into the well for recompletion, future workovers and present imminent danger of well integrity. Using two simulation scenarios, casing structural integrity was investigated in both radial and axial configurations under the mechanics of a combine system-casing, cement and formation rock. Results obtained show that time dependent rock slippage - creep during stimulation lead to an increase transverse displacement and corresponding stresses on the casing. In addition, the effect of combined loading results in significant increase in both displacements and stresses that can cause radial and axial permanent failure of the casing. This explains the lack of access in the casing during multi-stage hydraulic fracturing and future well intervention and recompletions and increased current understating of the downhole dynamics and casing structural integrity during volume fracturing.
\end{abstract}

Key words: Casing Buckling, Rock Slippage, Fracturing, In-situ stresses, Shale Gas Wells

\section{Introduction}

Horizontal wells and hydraulic fracturing are key technologies that are commonly employed to develop shale gas and low permeability oil and gas reservoirs in recent years. However, numerous challenges prevent efficient drilling, completing and stimulating these wells as planned. For example, drill-cuttings accumulation increases with increase in wellbore inclination as established by (Busahmin et al., 2017). Shale gas and tight oil reservoirs exhibit very low permeability justifying the need for multi-stage stimulation to increase recoveries of oil and gas through hydraulic fracturing. Another feature of shale gas horizontal well is the very long lateral section. This property of the well prevent efficient deployment of casing in the lateral due to gravity, ledges and tight hole particularly in shale reservoirs.

In the process of hydraulic fracturing, the production casing is subjected to high internal pressure as noted by (Yan et al., 2017). Excessive stimulated segments and big pumping delivery rate during the volume fracturing process, complicate casing's mechanical behaviour which results in shear failure, leap and slip, around the horizontal section and change in in-situ stress field due to both drilling and stimulation (Chipperfield et al.; 2007; Hossain et al., 2010; Yin et al., 2018a; Lian et al., 2015). Consequently, the planned mulit-stage stimulation cannot be completed as expected (Tang et al. 2013; Yu et al. 2016, Brantley et al. 2014). Xing et al. 
(2017) established that shale gas horizontal wells suffered casing deformation because of complex stresses downhole during fracturing operations. Moreover, Lian et al. (2015) indicated that stress deficit and clustering perforations made horizontal well deformed radially and ' $S$ '-shaped deformation axially. Similarly, both Xi et al. (2017) and Wang et al. (2018) indicated that when a weak plane is activated in shale reservoirs, such activation and bedding caused casing shear deformation. Another reason for casing deformation was proposed by Hagshenas et al. (2017) and Liu et al. (2017) who noted that additional load is exerted on the casing by fracture slip through the wellbore. Liu et al. (2018) pointed out that local stresses and shear of weak formation are the main causes of casing deformation during fracturing. These local stresses are typically tangential, axial and radial resulting from in situ stresses. Depending on the degree of rock consolidation and the formation characteristics wellbore stability problems issues can develop during fracturing operations.

For example, Yin et al. (2018a), showed that shear deformation of casing was due to slip of shear fractures in shale gas reservoirs, based on curvature screening criteria. This study further revealed that slip displacement led to large transverse displacement and stress concentration points on the casing. In a different study, Yu et al. (2016) examined the effect of hydraulic fracturing on reservoir deformation and concluded that fractures caused casing and subsurface deformations. The study by Chen et al. (2017) identified fracture and bedding as the main internal factors responsible for casing deformation during hydraulic fracturing. Besides, when the casing is not properly centralised potential buckle points could manifest in the lateral section of the horizontal well (Mianguy and Innes 2018).

In summary, many factors are attributing to casing failure during hydraulic fracturing, resulting in different casing failure modes are being studied and documented in the literature (Yin et al. 2018b, Zhaowei et al., 2017; Li et al., 2012; Abou-Sayed et al., 2005). Nonetheless, another aspect that is presently receiving attention is multiple casing deformation points on lateral section of the well during fracturing as established by Xi et al. (2018) and Yan et al. (2017). However, this study examined both time dependent viscoelastic property of the rock (creep) and temperature during shale gas wells development (stimulation). Predicting the stresses and displacement that will be generated under a particular fracturing scenario in P110 casing grade is essential during this process. Ideally, a stage stimulation and tripping could simply take few hours under normal circumstance during shale gas fracturing. However, viscoelastic property of the rocks (particularly shales) can lead to a major wellbore instability such as collapse and fracture closure under creep load. This can lead to an expensive rig time of days if not weeks. Therefore, knowledge in critical parameters (under creep and temperature) as a function of time during multi-stage stimulation for shale gas wells is urgently required to further support design and installations to increase in stimulation success rate.

\subsection{Problem Description}

Both in-situ and induce stresses during shale gas development contributed to casing deformation. A wellbore drilled during drilling removes rock within the subsurface formation, which distorts the initial equilibrium of in-situ stress field. The distortion in the in-situ stresses are responsible for the resulting wellbore instability problems such as tight hole, casing collapse/buckling and perforation/fracture closure (Economides et al., 1998). Depending on the rock characteristics, well configuration, 
geometry, drilling fluids type; several wellbore stability issues could manifest (Busahmin et al., 2006). Besides, in almost all fracturing projects, high pumping pressure is required to overcome rock compressive stress particularly in a high geostress shale region (Xi et al. 2018). This pumping pressure and the hydrostatic pressure of the fracturing fluids intensify the distortion of the in- situ stresses- leading to a complex stress field around the wellbore (Lian et al. 2015). Figure 1 presents example cases of casing failure during shale gas well development based on a review by (Mohammed et al., 2019). As it can seen, Figure 1 (A \& B) show the effect of centraliser on casing deformations, while ( $C \& D)$ present buckling due to fracture and lead mould impression justifying casing deformation respectively.
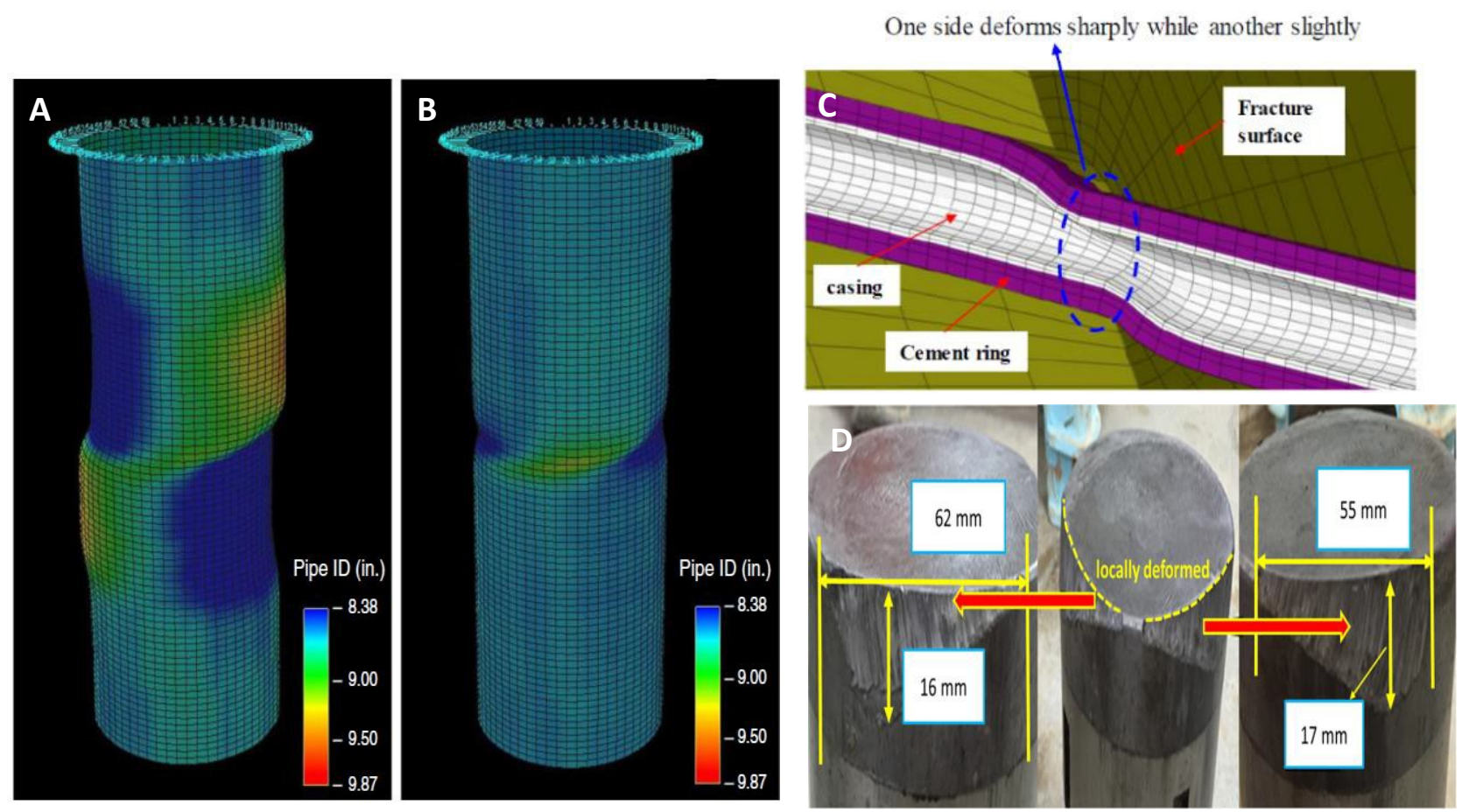

Figure 1 (A) 3D view of deformed casing- well F1 showing effect of centralisation (A) Non-Centralised (B) Centralised- Mianguy and Innes 2018. (C) Sectional view of casing simulation results due to natural fracture $\mathrm{Li}$ et al. 2017. (D) Lead mould washout from a buckled casing Yan et al. 2017.

The standard practice in the industry is to select, design, install, and operate the casing string based on anticipated downhole stresses using stress-check, wellcat and casing seat (Aasen and Pollard 2003, Wu et al., 2006, Liu et al., 2015) in both conventional and unconventional wells. However, this approach is limited and cannot sufficiently address the design requirement for unconventional wells where casing cement and formation system are bonded together with induced stresses during fracturing. Finite element analysis and numerical simulation can circumvent this limitation to predict the casing critical buckling parameters. Hence, using 2D and 3dimensional finite element model, casing critical buckling and factors influencing it are investigated based on the simulations and analyses.

Therefore, this study examined the time dependent viscoelastic property of the rock (creep) and thermal stress complexities during stimulation to quantify critical parameters on the production casing. The objective is to predict critical displacement, shear and von Mises stresses in the casing as a function of time. Using these 
parameters (results) and casing properties, the casing structural integrity is categorised as either elastically or plastically deformed/buckled over time. Knowledge in the stresses that will develop in the casing during fracturing under a particular circumstance is beneficial. In particular, one of the significance of this study is the results obtained from these analyses show that even without considering induce thermal loads, P110 casing grade cannot withstand shale slip displacement of $20 \mathrm{~mm}$ over a 30hours period. Hence, predicting critical parameters (under creep and temperature) as a function of time during multi-stage stimulation for shale gas wells is important. This will influence the selection, design and installation of casing to optimise the process and increase success rate in shale gas horizontal wells stimulation.

\section{Theoretical Background}

As explain above, a well drilled through a rock formation introduces a new stress field at the wellbore vicinity that can be large enough to cause borehole collapse. In addition, when a wellbore is loaded with hydrostatic pressure or other pressures at underbalance/overbalance with pore fluid pressure; wellbore collapse / 'wellbore breakdown' may be the result (Economides et al., 1998; Turon et al., 2006). Feng and Gary (2018) study established that fracture evolution could significantly change the in-situ stress near the wellbore. The direction of minimum principal stress near the hydraulic fracture path becomes parallel to the fracture, while in the area immediately ahead of the fracture tip the minimum principal stress tends to be perpendicular to the fracture. This led to a situation where the minimum horizontal stress grow without limit and cause casing deformation during fracturing (Beugelsdijk et al., 2000).

A larger perforation angle may cause a longer curving fracture section and a higher breakdown pressure. This phenomenon additionally causes major structural failure of both casing, cement and surrounding formation. Wang (2016) and Zhang et al. (2010) pointed out that with arrays of hydraulic fractures along horizontal wellsstress field changes induced by hydraulic fractures can lead to fracture interference and coalescence. The resulting complex fracture geometry may compromise or improve the effectiveness of the stimulation job, depending on the nature of the context. However, Mohr's Coulomb and Drucker Prager are among applied models to study rock failure criteria in geomechanics.

To understand a failure mechanism, one must apply a specific and compatible failure criterion. Geo-materials, such as sandstones and consolidated shales fails in shear, while for soft material such as clays, plastic compaction dominates the failure mechanism. For example, shear failure give rise to casing and cement failure while plastic deformation and compaction may cause casing buckling and collapse. Similarly, rock tensile failure can potentially cause casing connection failure such as part and creep loading may induce permanent deformation of the casing downhole.

Assuming a homogeneous, isotropic, linearly elastic rock mass being stressed below its yield limit, a stress field expressed in polar coordinates as vertical, tangential, and radial is given by the Kirsch solution (Jaeger et al., 2009)

$$
\sigma_{v}^{\prime}=g \int_{0}^{H} \rho_{b} d H-\propto p_{r}
$$

where: 
$\rho_{b}$ is the bulk density of the overburden layers and $\mathrm{H}$ is the depth.

$g=$ Acceleration due to gravity

$\sigma^{\prime}{ }_{v}=$ Overburden stress $\propto=$ Poroelastic constant usually between 0 and 1 .

$p_{r}=$ Pore pressure

The radial stress is expressed as:

$\sigma_{\text {rad }}^{\prime}=\frac{1}{2}\left(\sigma_{H \text { max }}^{\prime}+\sigma_{H \text { min }}^{\prime}\right)\left\{1-\frac{r_{w}^{2}}{r^{2}}\right\}+{ }_{\frac{2}{2}}^{1}\left(\sigma_{H \max }^{\prime}-\sigma_{H \min }^{\prime}\right)\left\{1-\frac{4 r_{w}^{2}}{r^{2}}+\frac{3 r_{w}^{2}}{r^{4}}\right\} \cos 2 \theta+\frac{r_{w}^{2}}{r^{2}}\left(p_{w}-p_{r}\right)$

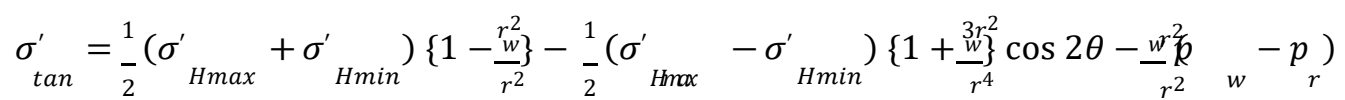

where;

$p_{w}=$ is the bottomhole pressure

$p_{r}=i s$ the reservoir pressure

$\theta=i$ s the angle measured from the direction of stress at wellbore radius $r=r_{w}$

However, creep experimental tests on rocks under constant stress as a function of time resulted in two different displacement. That is

$$
\varepsilon_{t}=\varepsilon_{e}+\varepsilon(t)
$$

In addition, Munson (2004) developed a dual mechanism creep model that consider rock creep behaviour under both temperature and differential stress as:

$\dot{\varepsilon}=\dot{\varepsilon}\left(\frac{\sigma_{e f f}}{\sigma_{\sigma_{0}}}\right) e^{\wedge}\left(\frac{Q}{R T_{0}}-\frac{Q}{R T}\right)$

Where: $\varepsilon_{t}=$ is the total strain due to aplied load

$\varepsilon_{e}=$ is the elastic strain

$\varepsilon(t)$

$=i s$ the creep as a fucntion of time which depend on the rhological properties of the rock

$\dot{\varepsilon_{0}}$ is the strain rate caused by steady state creep at a reference conditions, $\sigma_{e f f}$ is the effective creep stress; $\sigma_{0}$ is effective stress at reference conditions. $n$ is the exponent determine from laboratory test and $Q$ is activation energy; $R$ is universal gas constant, $T \& T_{0}$ are the reference temperature and rock temepetaure respectively.

However, if one consider the loading conditions that lead to rock failure during fracturing three failure modes may result. These are rock failure in tension, shear failure under sliding and shear failure from tear. For rock failure in tension (plane strain fracture), the critical energy equals the area under the traction - separation curve as noted by Wang (2015) on Figure 2. This however, can be related to rock fracture toughness according to (Kanninen and Popelar 1985, Economides et al., 1998).

$$
G_{i}^{c}=\frac{K_{i c}^{2}}{E}\left(1-\vartheta^{2}\right)
$$

Where $\mathrm{E}$ is Young's Modulus of the rock and $\vartheta$ is the rock Poisson's ratio. 

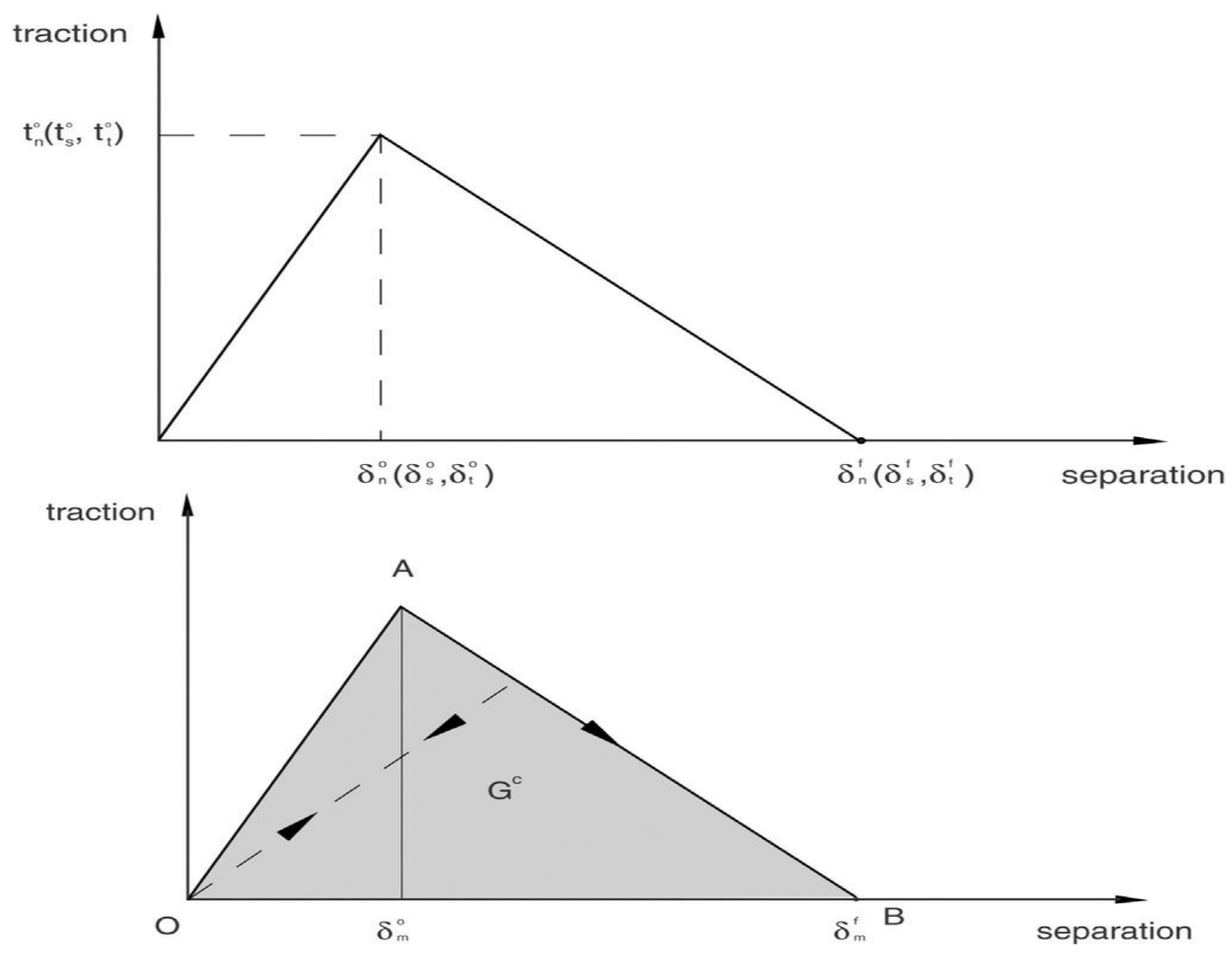

Figure 2 Linear traction-separation law for different modes (Wang 2015)

If any of the mentioned failure modes occur at any one instance during fracturing and the stress components reaches the maximum value in each case, the rock strength in that direction is expressed as:

$\left\{\underline{t}_{t_{n}^{0}}^{\underline{t}_{n}}\right\}^{2}+\left\{\underline{t}_{t_{s}^{0}}^{\underline{t}_{s}}\right\}^{2}+\left\{\underline{\underline{t}}_{t_{t}^{0}}^{\underline{t}^{0}}\right\}^{2}=1$

Where:

$t_{n}, t_{s}, t_{t}$ are the normal, first and second shear stress components respectively. In addition, $t_{n}^{0}, t_{s}^{0} t_{t}^{0}$ represent the tensile strength of the rock when deformation is purely perpendicular to interface and the shear stress in the first and second directions denoted by $\delta^{0}, \delta^{0}, \delta^{0}$ which correspond to the initial displacement and $\delta_{n}^{f}, \delta_{s} f, \delta_{t}^{f}$ represent the complete failure of the rock in these three directions as shown on figure 2. While the Macaulay bracket symbolised pure compressive stress that does not initiate damage to the rock.

For the steel casing, the tendency of plastic deformation depends on the radial, axial and tangential stresses. This phenomenon is essentially governed by the von Mises yield criterion; in which the casing strength is estimated by:

$\sigma_{V M E}=\sqrt{\frac{\left(\sigma_{\underline{A}}-\sigma_{\underline{t}}\right)^{2}+\left(\sigma_{\underline{t}} \underline{\underline{-\sigma_{r}}}\right)^{2}+\left(\sigma_{\underline{r}} \underline{\underline{-\sigma}} \underline{\underline{A}}\right)^{2}}{2}}$

Plastic deformation can be estimated from yield index (YI) which is defined by: 
$Y I=\frac{\sigma_{m}}{\sigma_{y}}$

Where:

$\sigma_{m}$ Von Mises stress, $\sigma_{A}, \sigma_{t}, \sigma_{r}$ represent the three principal stresses respectively. $\sigma_{y}$ is the casing yield strength.

In particular, axial stress is expressed as:

$\sigma_{A}=\frac{F_{A}}{A_{p b}}$

For radial stress two components are internal radial stress and external radial stress are:

$\sigma_{r e}=-p_{e}$

Similarly for internal radial stress

$\sigma_{r i}=-p_{i}$

For external tangential stress, we have;

$\sigma_{t e}=\frac{2 p_{i} r_{i}^{2}-p_{e}\left(r_{e}^{2} t r^{2}\right)}{r_{e i}^{2}-r^{2}}$

Also, for internal tangential stress;

$\sigma_{t i}=\frac{p_{i}\left(r_{e}^{2}+r_{i}^{2}\right)-2 p_{e}^{2} r_{e}^{2}}{r^{2}-r^{2}}$

It should be noted that radial and tangential (hoop stress) are derived from Lame's equation for stresses in a cylinder (Klementich and Jellison 1986). Moreover, Carslaw and Jaeger (1959) established the governing equation for heat transfer after an energy balance in solids materials.

\section{Finite element model (FEM)}

The initial stress analysis is linear static in ANSYS parametric design language (APDL) v.18.1 which examines shale rock, cement and P110 as one entity. A 2D geometry was developed and consist of casing, cement and formation rock modelled using solid element ( 8 nodes 183 ) which is ideal for modelling 2D structural solids with plane strain behaviour. This element is defined by 8 nodes having two degrees of freedom at each node: translations in the nodal $x$ and $y$ directions.

Next, a 3D finite element model that comprises the casing, cement and shale rock was developed in ANSYS v18.1 (ANSYS parametric design language - APDL) to simulate the mechanical behaviour of casing undergoing time dependent slippage during fracturing. Mesh sensitivity was firstly carried out to ensure convergence and results accuracy during our simulations study. The FE model has total of 18414 elements as shown on Figure 3. The modelling of scenario ' $b$ ' utilised 3D geometry with a $4000 \mathrm{~mm}$ casing length. The outer diameters of casing, cement and formation rock are; $127 \mathrm{~mm}, 168 \mathrm{~mm}$ and $468 \mathrm{~mm}$ respectively. The shale rock is assumed to undergo a $20 \mathrm{~mm}$ displacement over a 30-hour time dependent slippage during fracturing. The element type chose for this analysis is 'SOLID185'. It is used for 3-D modelling of solid structures. It is defined by eight nodes having three degrees of 
freedom at each node: translations in the nodal $X, Y$, and $Z$ directions. The element has plasticity, hyperelasticity, stress stiffening, creep, large deflection, and large strain capabilities. It also has mixed formulation capability for simulating deformations of nearly incompressible elastoplastic materials, and fully incompressible hyperelastic materials.

The front view (2D) of casing, cement and shale rock is shown in Figure $3(A)$ below. While the finite element model (FEM) is as shown in Figure 4 (B).

(B)

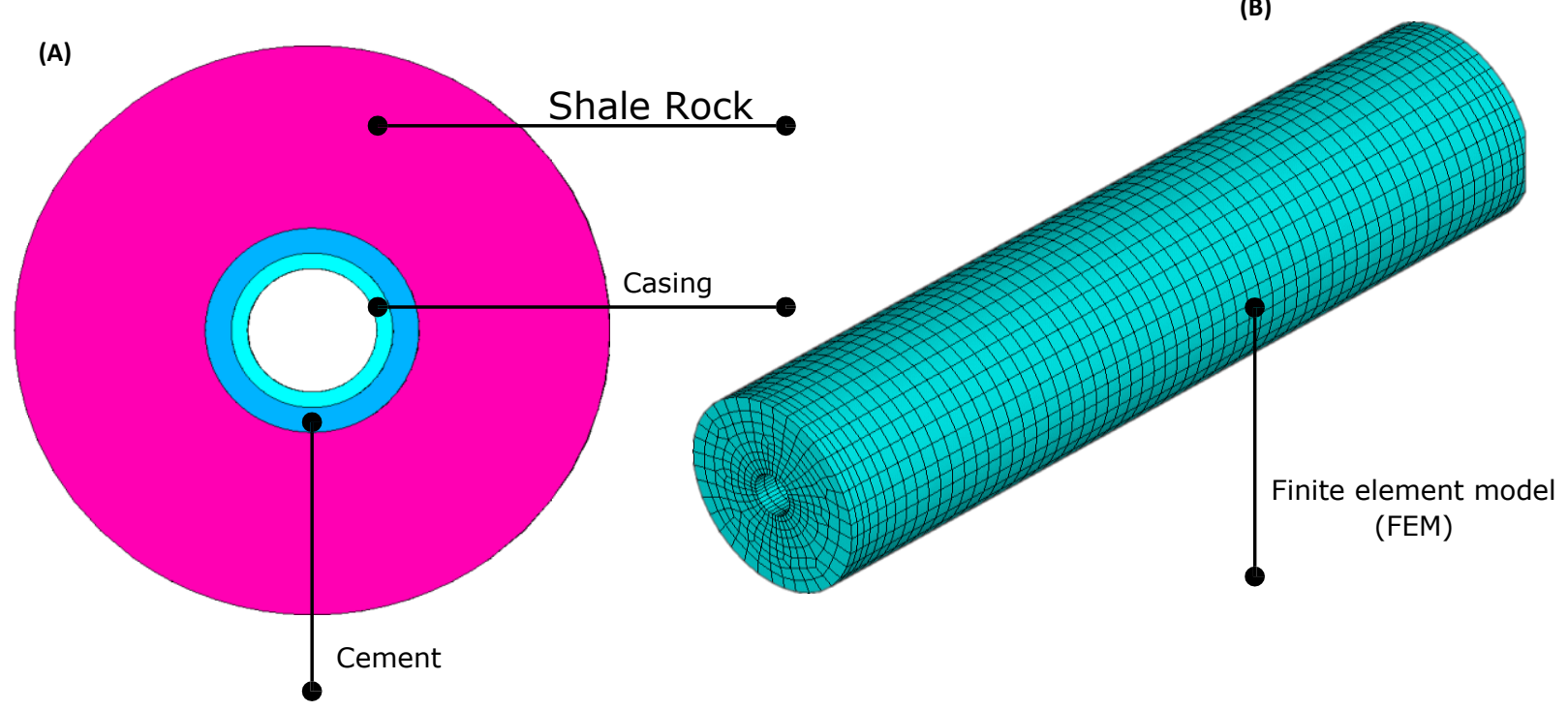

Figure 3 (A) 2D view of casing, cement and shale rock. (B) Finite element model (FEM) with 18414 elements

Materials description and properties used in the modelling are provided in Table 1.

\begin{tabular}{|l|l|l|l|l|}
\hline Material & $\begin{array}{l}\text { Young's Modulus } \\
(\mathrm{MPa})\end{array}$ & $\begin{array}{l}\text { Poisson's } \\
\text { Ration }\end{array}$ & $\begin{array}{l}\text { Coefficient of thermal } \\
\text { expansion }\left({ }^{\circ} \mathrm{F}\right)\end{array}$ & $\begin{array}{l}\text { Internal } \\
\text { diameter }(\mathbf{m m})\end{array}$ \\
\hline Casing P110 & 210000 & 0.3 & $6.9 \times 10^{-6}$ & 101.6 \\
\hline Cement & 7000 & 0.23 & $9.2 \times 10^{-6}$ & 127 \\
\hline Shale rock & 20900 & 0.18 & $1 \times 10^{-5}$ & 468 \\
\hline
\end{tabular}

In order to build confidence on the finite element model, a 3D nonlinear finite element model was utilised based on the study performed by Yin et al. 2018 (Figure 4). The cuboid rock block has the dimensions of $4000 \mathrm{~mm} \times 1200 \mathrm{~mm} \times 1200 \mathrm{~mm}$. A natural fracture with the dip angle $a$ and width of $\Delta d$ is created in the rock block (Figure 4). The rock block is divided into a static part and a mobile part (or two mobile parts). The normal displacements on the settled part surface is zero. The slip displacement of the mobile part is represented as $s$. 


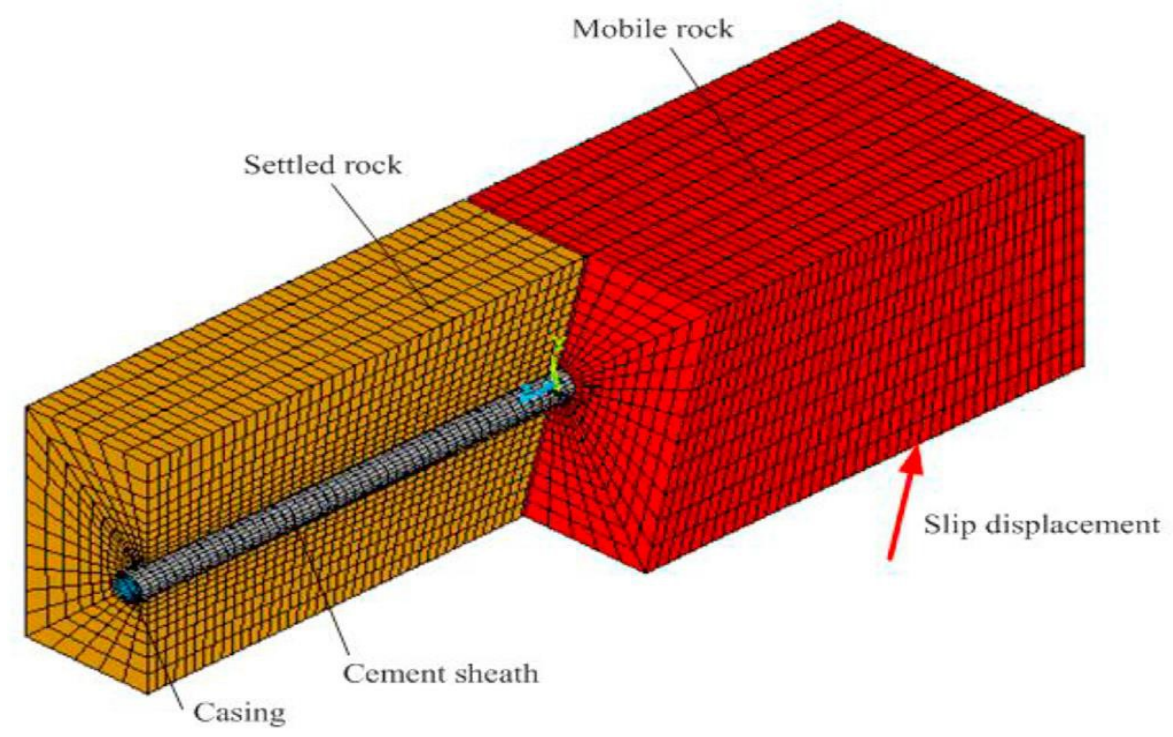

Figure 4 Finite element model (After Yin et al. 2018)

\subsection{Simulation Scenarios}

Two scenarios are investigated to compute the production casing's critical parameters during fracturing operations.

(i) Simulation Scenario 'a': This scenario assumed differential overburden stress owing to rock removal acts on the casing externally resulting from hydraulic fracture after a stage stimulation. The scenario examined the mechanics of a combined system (casing, cement and shale rock) to reveal how differential stress (overburden) lead to casing deformation. We also assumed the stress analysis to follow thin wall cylinder theory and the external pressure act perpendicular to the crosssectional surface of the outer shale rock as shown on Figure 5 (a). Therefore, this scenario analyses P110 casing grade under different loading conditions based on casing specifications provided in Table 1. $45 \mathrm{MPa}, 60 \mathrm{Mpa}, 75 \mathrm{MPa}$ and $90 \mathrm{MPa}$ are applied and the corresponding simulation performed to investigate the casing structural integrity.

(ii) Simulation Scenario ' $b$ ': Scenario ' $b$ ' refers to the simulation of a time dependent formation slippage (creep) during hydraulic fracturing. Similarly, this scenario examined the mechanics of a combined system (casing, cement and formation rock) as one single entity. The linear static stress analysis on P110 casing grade predicted the critical displacements, stresses and time for such critical values to be attained. In addition, the scenario also examined the effect of static temperature on the critical parameters. The physical model of this scenario is shown on Figure 5 (b). 


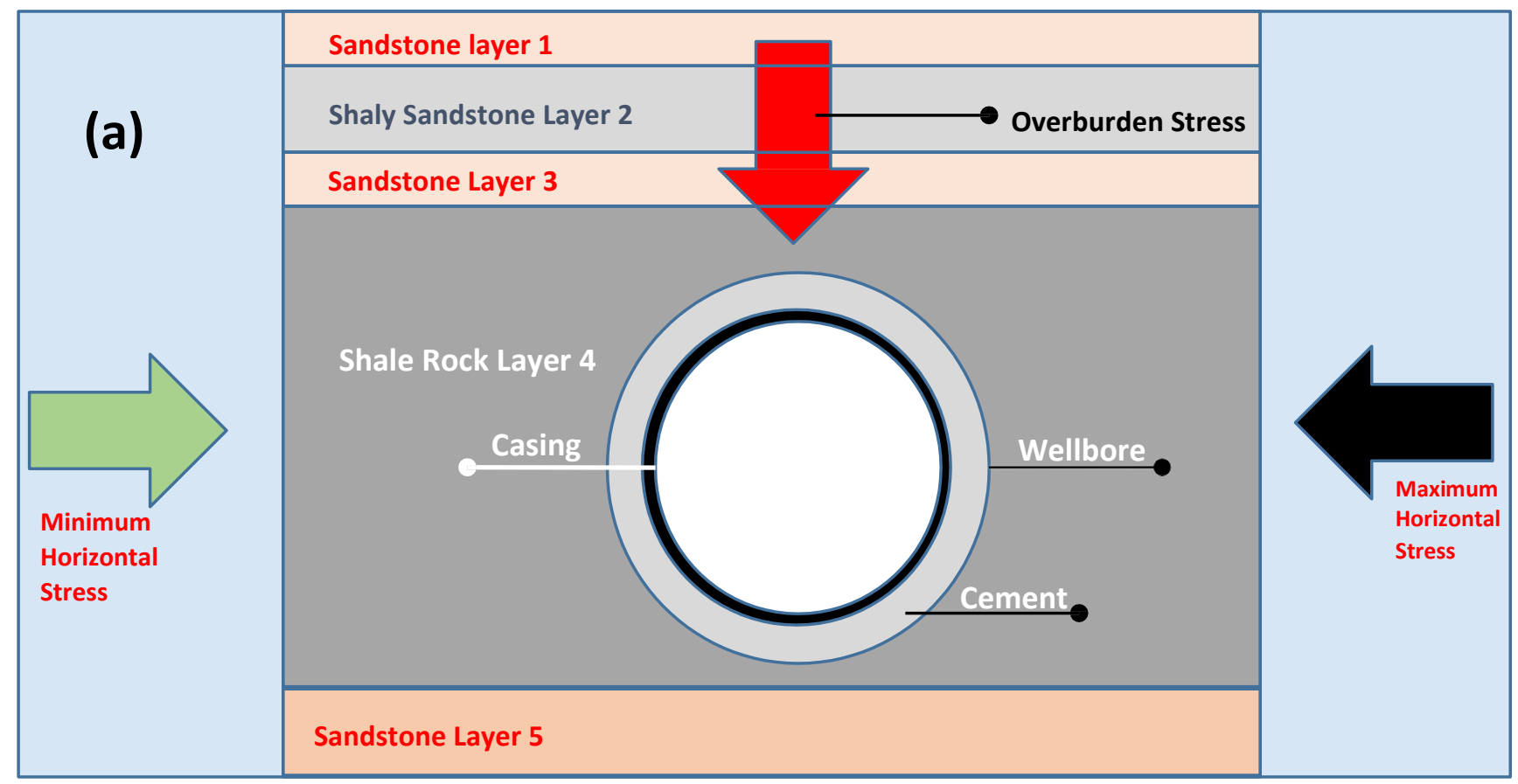

(b)

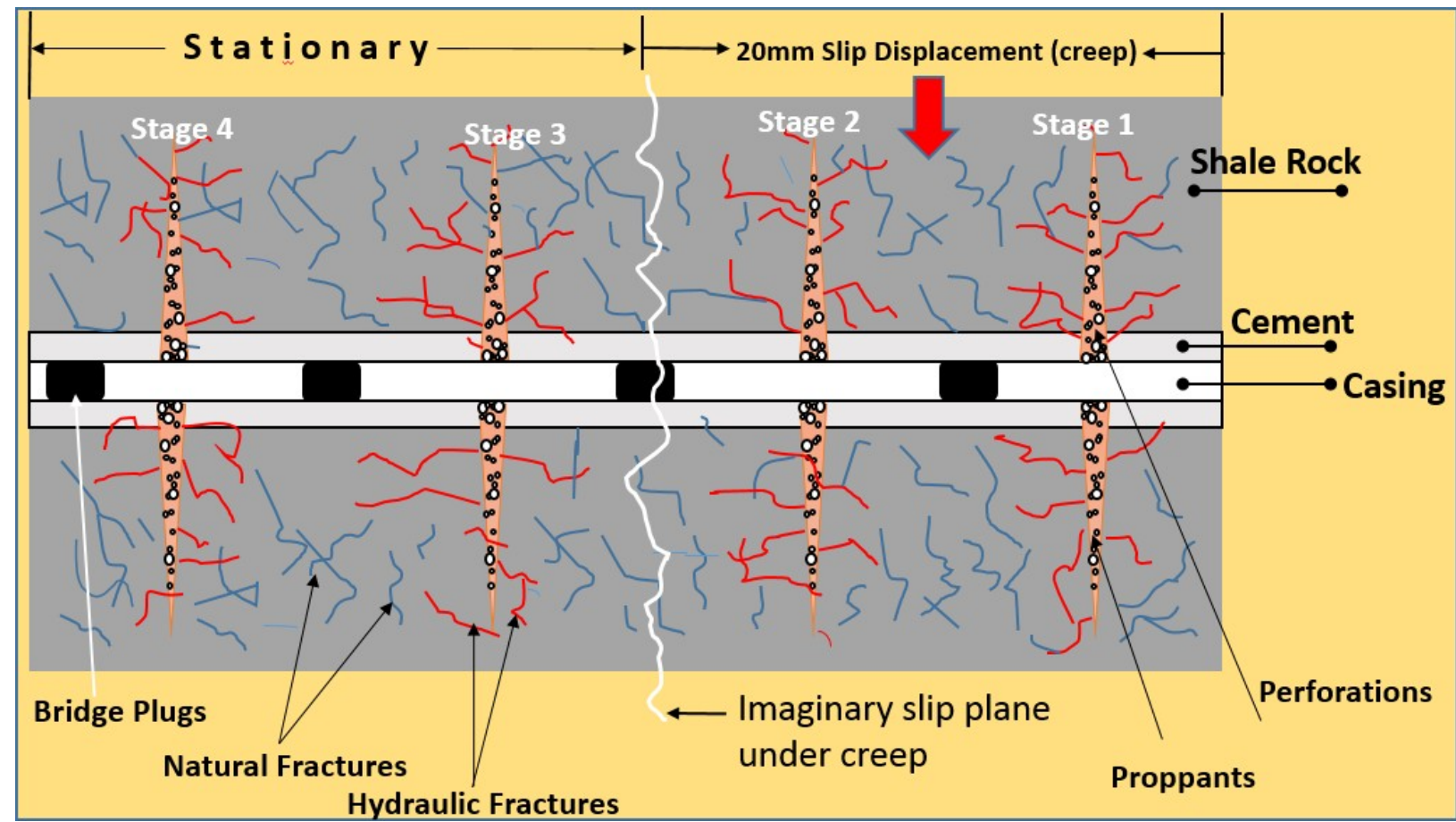

Figure 5 schematics of simulation scenarios (' $a$ ' and ' $b$ ')

The casing was constrained in all degree of freedom to avoid rotation. Systematic investigation of the casing deformation was carried out based on casing data and slip displacements for a time dependent slippage of 30 hours. A $20 \mathrm{~mm}$ displacement was applied on the shale rock to simulate its effect on the casing. Again, linear elastic is assumed to predict the critical displacements and stresses in the casing. Further, simulation scenario ' $b$ ', results relating to time dependent slip displacement after a stage stimulation are analysed. A representative sample of contour plots of both von Mises stress and transverse displacement along the axial length of the casing within critical time (hours) at which the casing will likely buckled was studied. A path was defined along the axial length of the casing $(4000 \mathrm{~mm})$ and extracted data points of 
shear stress, transverse displacement and von Mises stresses corresponding to different times of concern.

\section{Results and Discussions}

Although Yin et al. (2018) assumed frictional contact between shale, cement and formation rock, this study assumed bonded relationship between casing, cement and formation rock. Simulation results for lateral displacements are in good agreement as per the study of Yin et al. (2018) with less than 5\% error accounting for geometric and material nonlinearity. These results are plotted and presented in Figure 6.

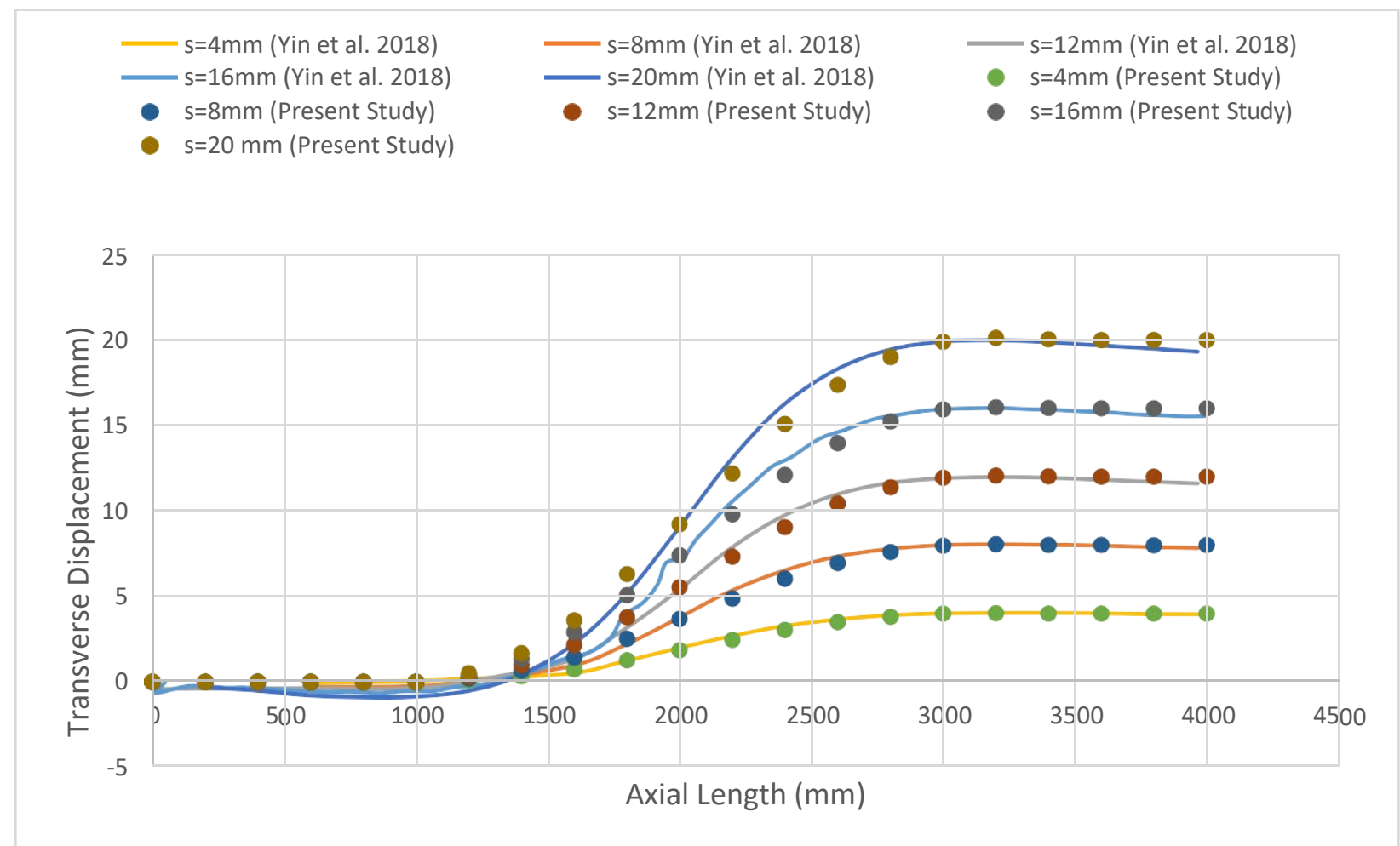

Figure 6 sample result comparison for validation

The two simulation scenarios described above are examined independently. For simulation scenario 'a', radial displacements, von Mises stresses, shear stress, hoop stresses under different external loads on a defined 'circular path' of radius $115 \mathrm{~mm}$ (appx. mid-point) through the casing thickness were investigated.

In-situ stress field could lead to a severe tangential stress (hoop stress) or even cause wellbore collapse attesting the view of (Economides et al., 1998; Turon et al., 2006). Also, using in-situ stress data and analyses Figure 7 presents the criticality of tangential stress in both vertical and horizontal wells before and after drilling. The initial tangential stress in vertical well was $48 \mathrm{MPa}$ before drilling and 69MPa after drilling. In contrast, the initial tangential stress in horizontal well before drilling was $48 \mathrm{MPa}$. However, owing to rock removal, the tangential stress reaches a maximum of $110 \mathrm{MPa}$. As seen on Figure 7, stress variation in horizontal well is much more severe than in vertical well due the to overburden pressure. Under this situation wellbore stability becomes critical. Using equation (1), the tangential stress can be calculated as follows:

$\sigma_{\theta}=\sigma_{H \max }+\sigma_{h \min }-2\left(\sigma_{H \max }+\sigma_{h \min }\right) \cos 2 \theta-\left(P_{w}-\alpha P_{r}\right)$ 


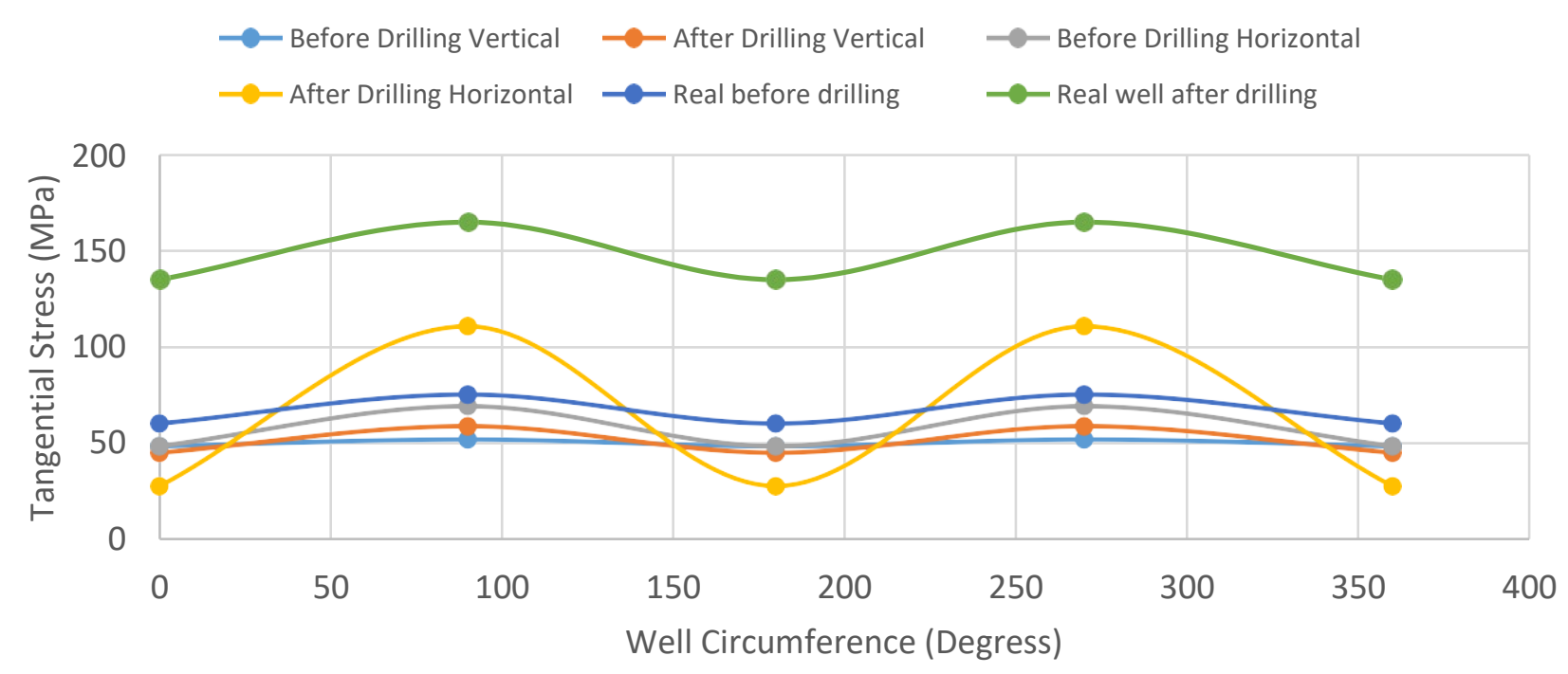

Figure 7 Tangential stress distribution along wells

Figure 8 ( $a$ and $b$ ) presents contour plots of the radial displacement and von Mises stress in the casing under 90MPa differential overburden stress. As it could be seen, that the casing deforms slightly owing to external load applied. The maximum radial displacement recorded under this loading was $0.163637 \mathrm{~mm}$ on the high side of the casing. While the minimum occurred at the low side of the casing is $0.106 \times 10^{-03} \mathrm{~mm}$. However, this indicates that the differential stress resulting from overburden affects the casing only slightly. Moreover, the von Mises stress generated (201MPa) is below the casings' yield strength of $758 \mathrm{MPa}$. Therefore, provided the casing is centrally cemented there is low risk of its failure under the influence of differential overburden - external load. These contour plots are presented on Figure 8( $a$ and $b)$. Hence, and elastic failure of the casing results under this circumstance.

Figure 8 ( $c$ and d) presents a representative sample of contour plots of both critical displacement and von Mises stress. The rock failure during fracturing leads to the corresponding differentials in stress and displacements as established theoretically by (Wang et al. 2015). Hence, the rock failure leads to casing buckling depending on the stress and displacement of the rock and the orientation of the principal stresses downhole. As it can be seen, simulation result show the critical displacement calculated is $14 \mathrm{~mm}$, while the corresponding critical von Mises stress is approximately $742 \mathrm{MPa}$, which will be attained in the time-space of 21 hours as shown. These results show the casing's critical time of buckling after a stage stimulation because $742 \mathrm{MPa}$ is $97.8 \%$ of the $758 \mathrm{MPa}$ limit for P110 casing grade.

Furthermore, under the same boundary condition, different reservoir temperatures are examined and corresponding simulations performed. For example at a temperature of $300^{\circ} \mathrm{F}\left(232^{\circ} \mathrm{C}\right)$, the displacement recorded was $13.117 \mathrm{~mm}$ while corresponding von Mises stress is $714 \mathrm{MPa}$. However, under this temperature, the time taken to reach critical displacements and stresses is reduced from 21 to 18.5 hours. This represents a $11.9 \%$ reduction in time taken to reach critical load in comparison to initial simulation results. Also when the temperature is further increased to $450^{\circ} \mathrm{F}$, critical displacement and von Mises are $12.3 \mathrm{~mm}$ and $741 \mathrm{MPa}$ respectively as shown in Figure 8 (e and f). When compared to initial simulations; 
temperature has caused a reduction of time taken to attain critical values from 21 to 17 hours, representing a 19\% reduction.

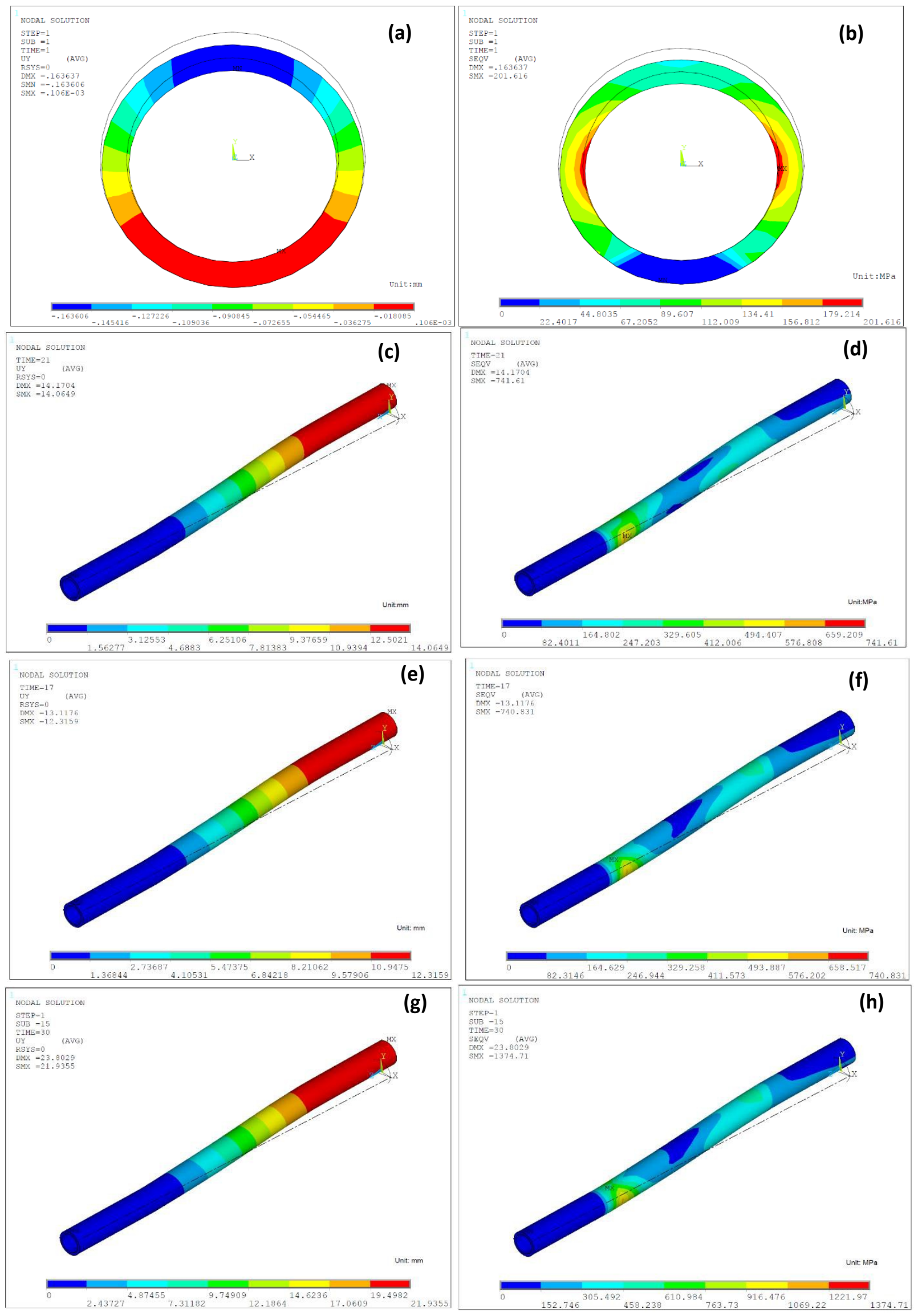


Fig. 8 contour plots of casing displacements and von Mises stresses

In the end, considering the complete 30 hours period, $24 \mathrm{~mm}$ displacement and $1375 \mathrm{MPa}$ von Mises stress is generated under the combine loading conditions (creep and temperature). Based on this result the casing is plastically buckled and permanently failed (Figure $8 \mathrm{~g} \& \mathrm{~h}$ ).

\subsection{Scenario 'a' Result Analysis}

Due to the significance of hoop stress in pressure vessel design, different differential external load ranging from 45 to $90 \mathrm{MPa}$ are applied and simulation performed in each case. Figure 9(a) presents various hoop stresses along the circumference of the casing. As it can be seen fluctuating compressional stresses are generated along the casing circumference as shown. However, this fluctuating compressional stresses are inadequate to cause the casing permanent failure as shown on Figure $9(\mathrm{a}-\mathrm{c})$. Although, the maximum radial stress recorded on contour plot is $201 \mathrm{MPa}$, the corresponding radial stress recorded along the path was $186 \mathrm{MPa}$ in compression as shown on Figure 9(b) and similarly, the maximum von Mises on this path is $150 \mathrm{MPa}$ Figure 9(c).
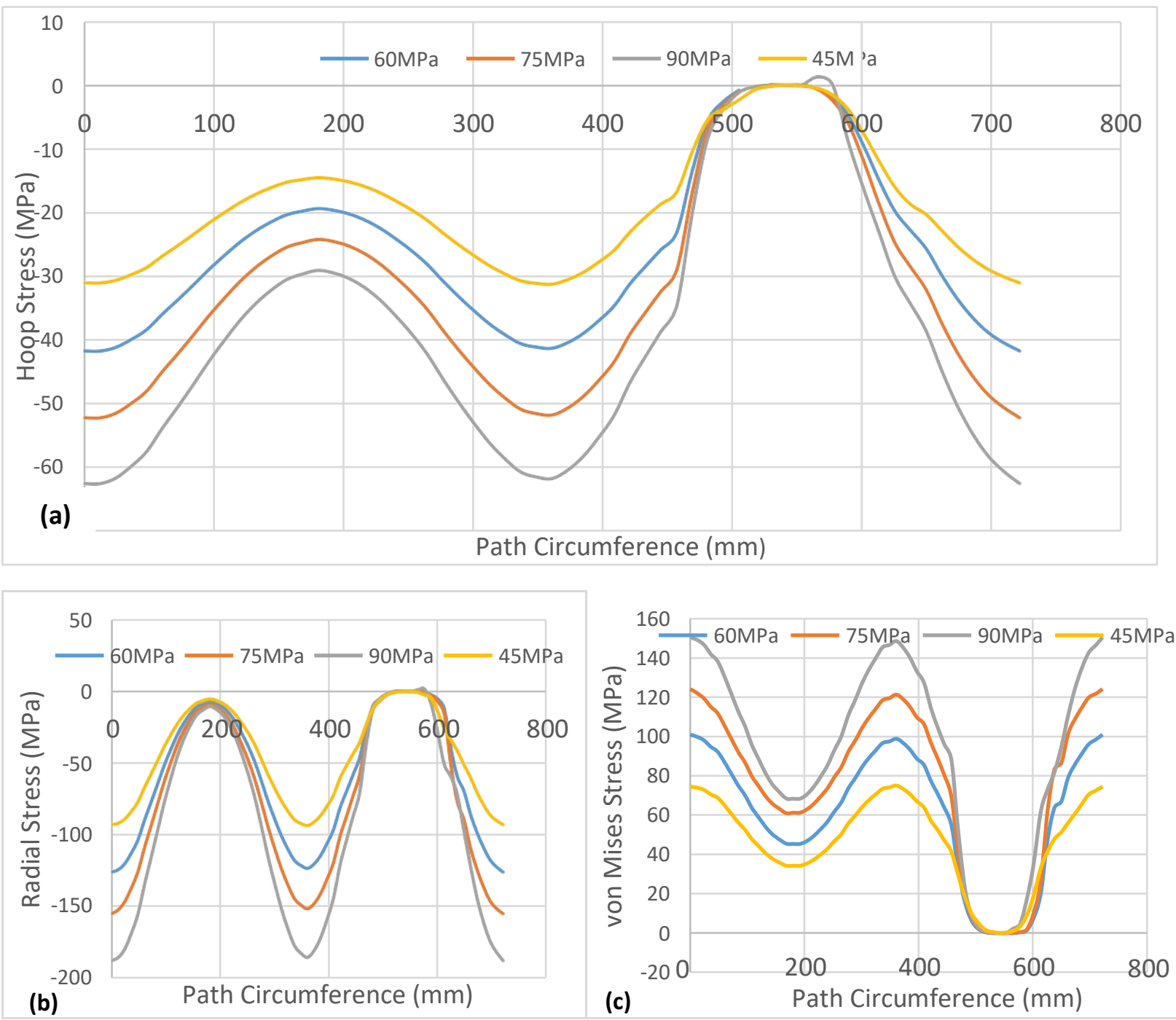

Figure 9 (a) Hoop stress under different differential loads (b) Radial stress along path circumference (c) von Mises stress with corresponding differential loads along path. 
In addition, different radial displacement and shear stresses corresponding to these differential overburden loads are presented on Figure 10 ( $a$ and $b$ ) respectively. The maximum displacement occurring at high side as shown.

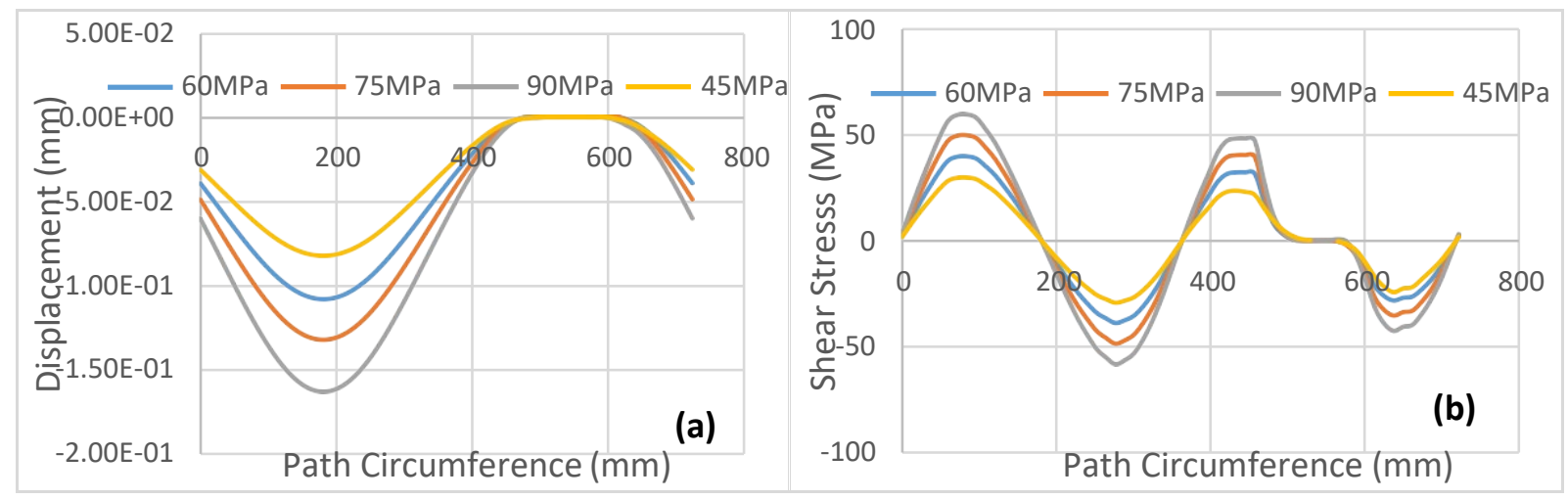

Figure 10(a) presents radial displacement (b) shear stresses

\subsection{Scenario 'b' Result Analysis}

Even though the modelling considers formation rock, cement and the casing as one entity, however, formation rock, cement were suppressed to enable the visualisation of the innermost casing's result as it is the objective of the analysis. Furthermore, a path was created along the axial length of the casing to observe the distribution of shear stresses, displacements, von Mises within the range of 5-30 hours as shown.

Figure 11 (a) presents various shear stresses at five hours interval for the period simulated. It indicates the tension and compression exists within the casing with a neutral section around the mid-point (1500-2500mm). In addition, this plot revealed that with an increase in the stimulation period, a corresponding increase in the shear stresses develops. However, the fundamental message on this plot is that casing may plastically buckle at low shear stresses (10-15MPa) which is well below the casing yield strength of $758 \mathrm{MPa}$.

Figure 11 (b) presents the transverse displacement distribution along the defined path for various periods. At the axial distance of $1000 \mathrm{~mm}$, transverse displacement is constant because the casing is constrained in all degree of freedom. However, beyond this point, transverse displacement continues to increase with an increase in the time interval. This reaches a maximum of $20 \mathrm{~mm}$ at the end of 30 -hour period at an axial distance of 3100 to $4000 \mathrm{~mm}$. This should not be confused with contour plots result that predicted the critical displacement of $14 \mathrm{~mm}$ corresponding to 21 hours slip period in Figure 8( $c$ and $d$ ). The casing will fail before the 30hour period based on the comparison with casing strength. 

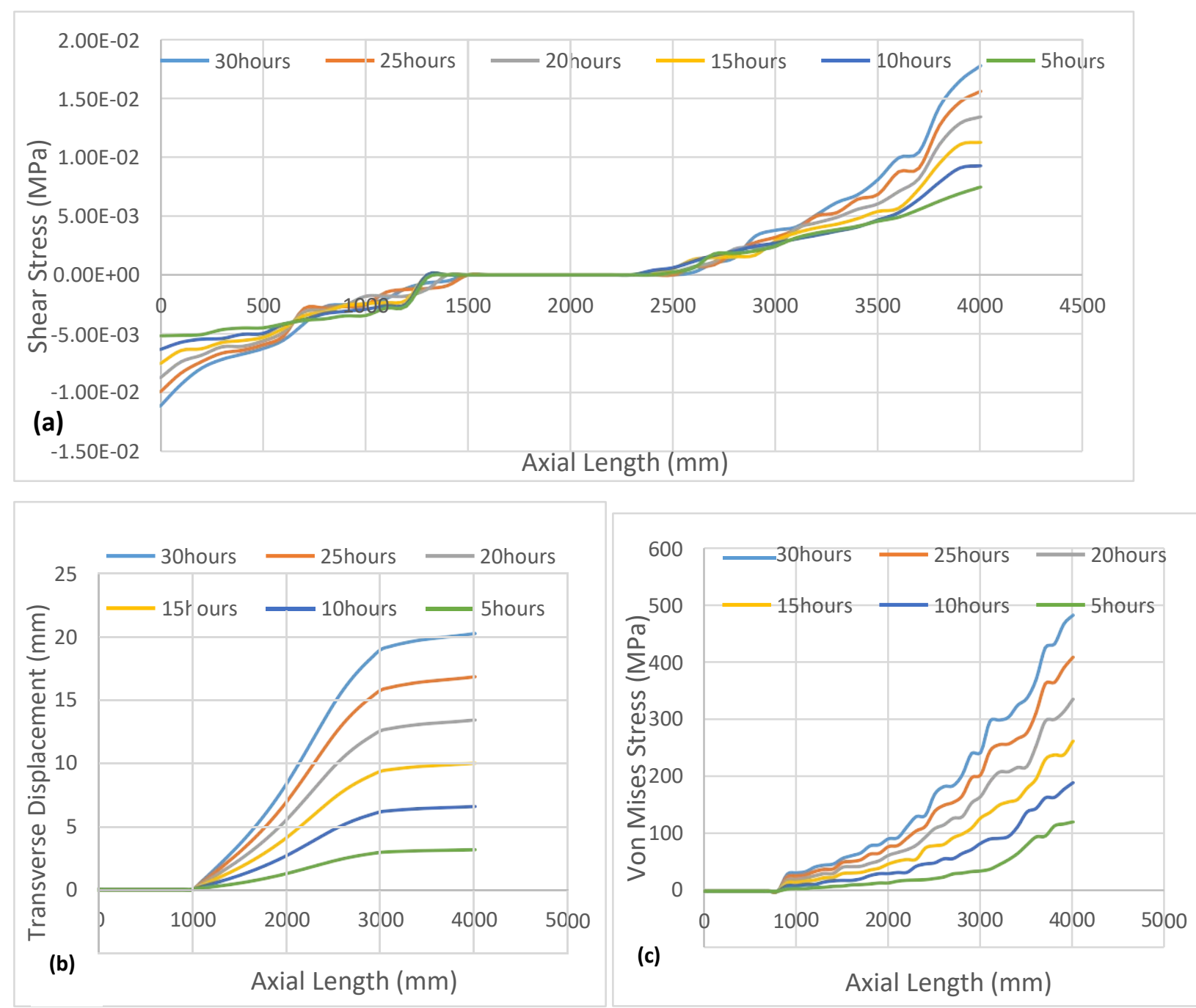

Figure 11 plots of (a) shear stress distributions along defined path at different time periods (b) Transverse displacements at various time interval and (c) 'Sort' von Mises stress distribution.

Figure 11 (c) presents mapped von Mises stresses plotted along the axial length of the casing. This plot represents 'sort' data points along the defined path. It also shows that von Mises stresses increase with an increase in displacement and period. Additionally, by using $2 \% 100 \mathrm{ft}$, the corresponding deflection is calculated and plotted on Figure 12. As expected, the maximum deflection on the casing occurred after a 30 hour displacement corresponds to $7.8^{\circ}$. Meanwhile, the minimum deflection computed is at $1.2^{\circ}$, which occurred after five hours of slippage. 


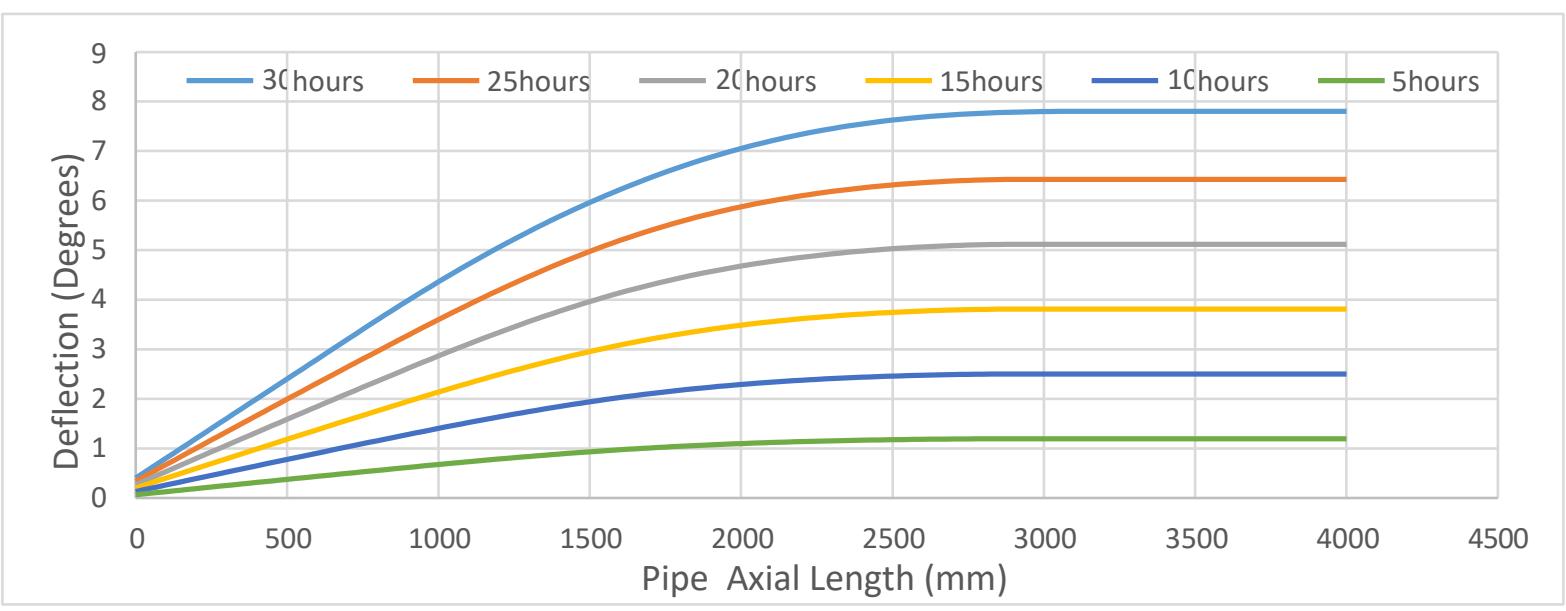

Figure 12 The angular deflection of casing under various slip periods.

\subsection{Effect of temperature on casing performance}

Using the same scenario 'a' influence of static temperature on casing under 45MPa external loading is investigated. Four different temperatures of 68, 150, 300 and $450^{\circ} \mathrm{F}$ are simulated to compute the incremental stress and von Mises stresses in the casing. As, expected, it was found that the increase in temperature leads to an increase in both stress and displacement as shown on Figure 13 respectively. The key finding here is that at a temperature of $150^{\circ} \mathrm{F}\left(65^{\circ} \mathrm{C}\right)$ to displacement increased by $62.09 \%$. Additionally, under these conditions of external load and thermal loads von Mises stress increased to $633 \mathrm{MPa}$ from the initial 100.7 MPa. As such, under the combine influence of differential overburden stress and temperature, casing failure is highly likely. For example, at $45 \mathrm{MPa}$ differential load and temperature of $300^{\circ} \mathrm{F}$ $\left(149^{\circ} \mathrm{C}\right)$ von Mises was $1125 \mathrm{MPa}$ which is much higher than the casing yield strength of $758 \mathrm{MPa}$. It can therefore be concluded under these combined loading conditions; both P110 and Q125 casing grade will fail plastically as shown on Figure 13.
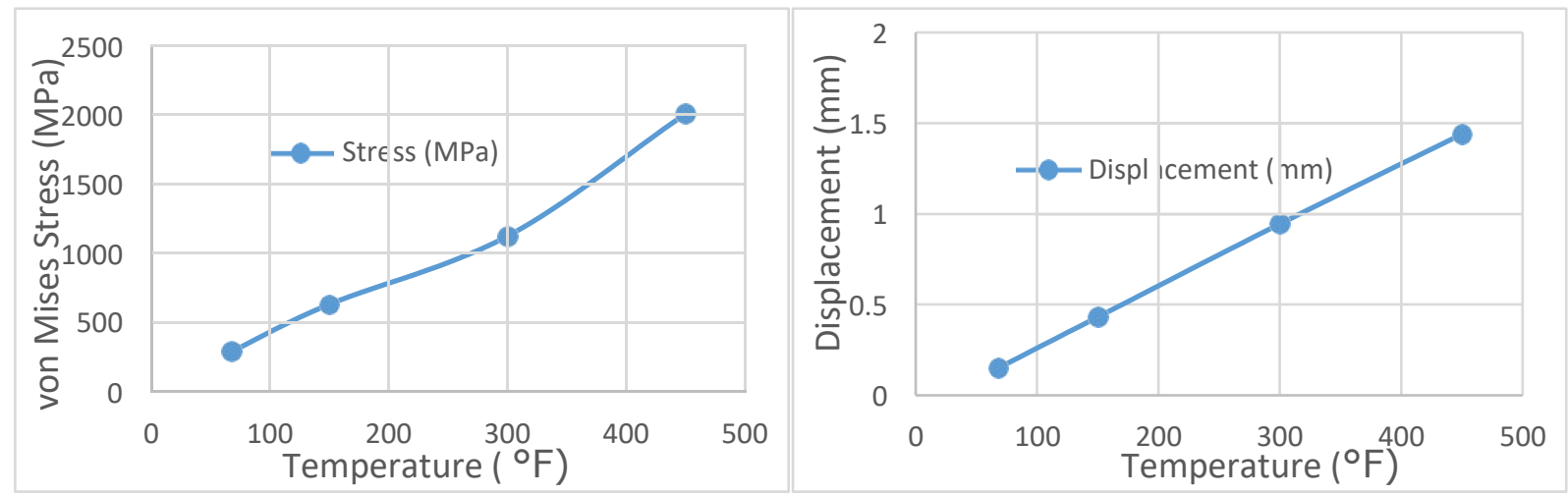

Figure 13 effect of temperature on casing stress and displacement.

To understand the role of temperature on critical displacements, shear and von Mises stresses, as well as the time to attain these critical values; another simulation was conducted with P110 at temperatures of $68,150,300$ and $450^{\circ} \mathrm{F}$. Results obtained show that temperature induces additional stress and displacement thereby reducing the time taken to attain critical values. For example, at a temperature of $150^{\circ} \mathrm{F}$, the critical displacement is $13.76 \mathrm{~mm}$ with corresponding von Mises $713 \mathrm{MPa}$. 
Furthermore, when the temperature is increased to $300^{\circ} \mathrm{F}$, the displacement reduces only a little with approximate von Mises stresses of 714MPa.

Figure 14(a) presents the effect of various temperature on casing strength. It indicates that the increase in temperature induces additional stress and displacement in the casing. For example, when the reservoir temperature is assumed to be $450^{\circ} \mathrm{F}$, the P110 casing could not sufficiently meet the stress requirement. In addition, higher strength casing grade Q125 will only bear these stresses below the 19-hour slip period. Beyond this time, it will fail as shown on Figure 14(a). As it is expected, higher temperatures lead to additional thermal loads on the casing; the critical time also reduces significantly owing to temperature increase as shown in Figure 14(b).

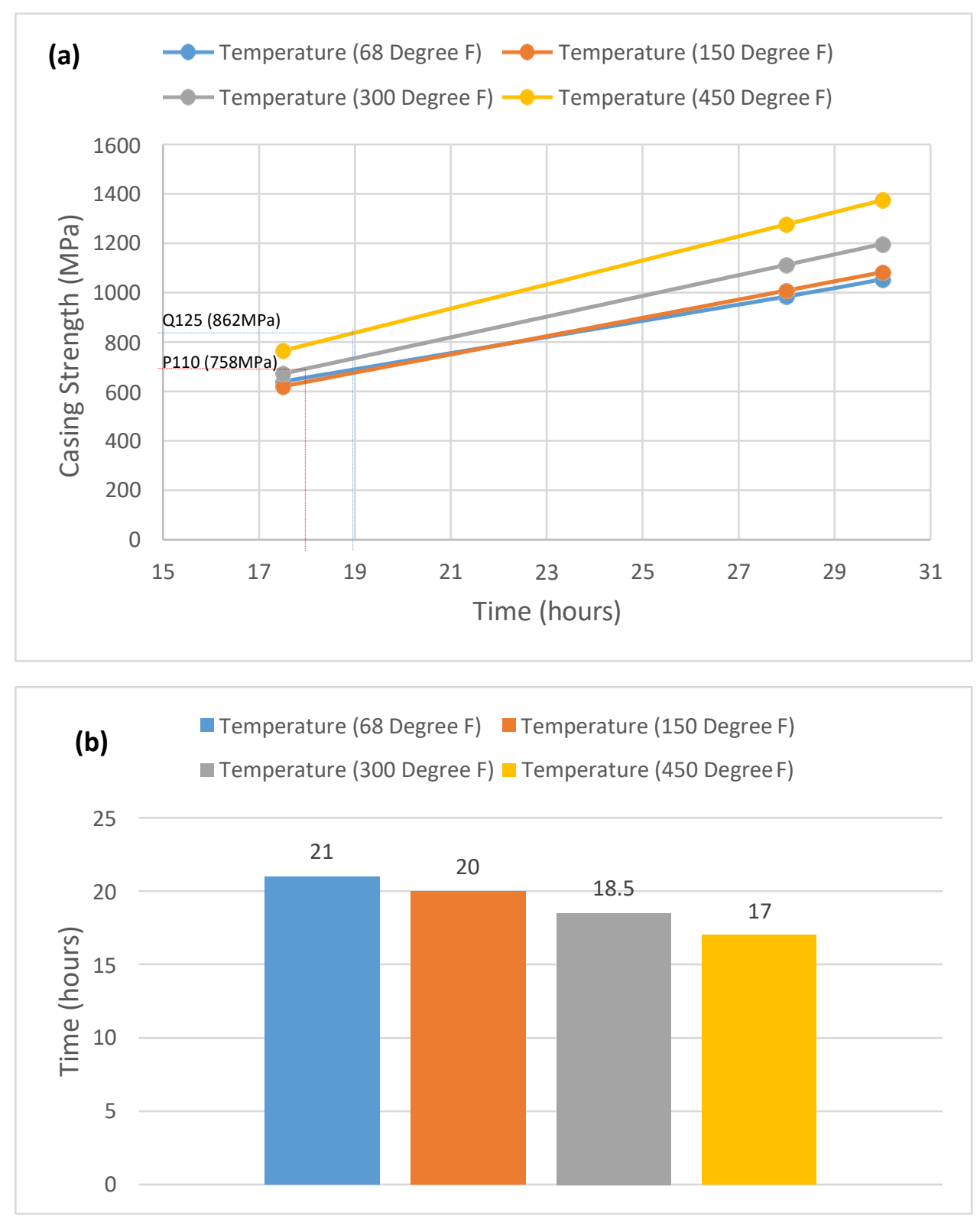

Figure 14 (a) Effect of temperature on casing strength as a function of time. (b) Effect of temperature on critical time to casing failure.

\section{Conclusion}


Casing failure as a function of time, temperature and constant slip displacement was simulated and critical parameters influencing casing buckling identified and quantified. Simulation results from these analyses show that even without considering induce thermal loads, P110 casing grade cannot withstand shale slip displacement of $20 \mathrm{~mm}$ over a 30 hours period. Moreover, at $14 \mathrm{~mm}$ casing displacement, shear stresses of 10-15 MPa developed along the defined path. This suggests that at very low shear rates casing buckling could occur. Assuming the $20 \mathrm{~mm}$ displacement to occur during fracturing, at the toe in the horizontal well; it means the casing will immediately buckle plastically and access to the well for the subsequent stages will be difficult or even impossible.

When we consider the effect of temperature on the casing buckling, temperature reduces the time taken to reach critical values. In fact, this can be significant. For example, when the temperature is increased to $450^{\circ} \mathrm{F}$ from the initial $68^{\circ} \mathrm{F}$, critical time reduced from 21 to 17 hours - which represent $19 \%$ reduction keeping other parameters constant. This clearly shows that temperature plays a decisive role in determining when the casing is buckled. Overall, increase in temperature and differential creep load lead to increase stresses and displacements in the casing. Findings in this study could serve as a basis for further improvements in the selection, design, installation and operation of the casing during shale gas development process based on critical parameters investigated and reported.

\section{Acknowledgement}

We would like to acknowledge financial funding by Petroleum Technology Development Fund (PTDF- Abuja Nigeria) under its overseas scholarship scheme for Auwalu Mohammed PhD scholarship. Grant Reference Number: PTDF/ED/PHD/MAI/1048/17

\section{References}

Aasen, J.A. \& Aadnøy, B.S. 2003, "Fully three-dimensional well design improves margins in critical wells", SPE/IADC Middle East.

Aasen, J.A. and Pollard, M., 2003. Casing Design-Review of Design Methodology.

Abou-Sayed, A.S. \& Zaki, K.S. 2005, "A mechanistic model for formation damage and fracture propagation during water injection", SPE European Formation Damage Conference, Society of Petroleum Engineers.

Beugelsdijk, L.J.L., De Pater, C.J. and Sato, K., 2000, January. Experimental hydraulic fracture propagation in a multi-fractured medium. In SPE Asia Pacific conference on integrated modelling for asset management. Society of Petroleum Engineers.

Brantley, S.L., Yoxtheimer, D., Arjmand, S., Grieve, P., Vidic, R., Pollak, J., Llewellyn, G.T., Abad, J. \& Simon, C. 2014, "Water resource impacts during unconventional shale gas development: The Pennsylvania experience", International Journal of Coal Geology, vol. 126, pp. 140-156.

Busahmin, B., Saeid, N.H., Alusta, G. and Zahran, E.S.M., 2017. Review on hole cleaning for horizontal wells.

Carslaw, H.S. and Jaeger, J.C., 1959. Conduction of heat in solids. Oxford: Clarendon Press, 1959, 2nd ed.

Chen, Z., Shi, L. \& Xiang, D. 2017, "Mechanism of casing deformation in the Changning-Weiyuan national shale gas demonstration area and countermeasures", Natural Gas Industry B, vol. 4, no. 1 , pp. 1-6.

Chipperfield, S. 2007, "Shear Dilation Diagnostics: a New Approach for Evaluating Tight Gas Stimulation Treatments. SPE 106289, Hyd", Frac. Tech. Conf., College Station, Texas, January.

Economides, M.J., Watters, L.T. and Dunn-Norman, S., 1998. Petroleum well construction (pp. 8-10). West Sussex, England: John Wiley \& Sons.

Feng, Y. and Gray, K.E., 2017. Parameters controlling pressure and fracture behaviors in field injectivity tests: A numerical investigation using coupled flow and geomechanics model. Computers and Geotechnics, 87, pp.49-61. 
Haghshenas, A., Hess, J.E. and Cuthbert, A.J., 2017, January. Stress Analysis of Tubular Failures During Hydraulic Fracturing: Cases and Lessons Learned. In SPE Hydraulic Fracturing Technology Conference and Exhibition. Society of Petroleum Engineers.

Hossain, M. \& Amro, M. 2010, "Drilling and completion challenges and remedies of CO2 injected wells with emphasis to mitigate well integrity issues", SPE Asia Pacific Oil and Gas Conference and Exhibition Society of Petroleum Engineers.

Jaeger, J.C., Cook, N.G. and Zimmerman, R., 2009. Fundamentals of rock mechanics. John Wiley \& Sons.

Klementich, E.F. and Jellison, M.J., 1986. A service-life model for casing strings. SPE Drilling Engineering, 1(02), pp.141-152.

Lian, Z., Yu, H., Lin, T. \& Guo, J. 2015, "A study on casing deformation failure during multi-stage hydraulic fracturing for the stimulated reservoir volume of horizontal shale wells", Journal of Natural Gas Science and Engineering, vol. 23, pp. 538-546.

Li, J., Guo, B., Gao, D. \& Ai, C. 2012, "The effect of fracture-face matrix damage on productivity of fractures with infinite and finite conductivities in shale-gas reservoirs", SPE Drilling \& Completion, vol. 27, no. 03, pp. 348-354.

Liu, W., Yu, B. \& Deng, J. 2017, "Analytical method for evaluating stress field in casing-cementformation system of oil/gas wells", Applied Mathematics and Mechanics, vol. 38, no. 9, pp. 12731294.

Liu, Z., Samuel, R., Gonzales, A. \& Kang, Y. 2018, "Analysis of Casing Fatigue Failure During Multistage Fracturing Operations", Abu Dhabi International Petroleum Exhibition \& Conference Society of Petroleum Engineers.

Liu, Z., Samuel, R., Gonzales, A. and Kang, Y., 2015, November. Casing Integrity: Strain-Based Fatigue Life Estimation Coupled with Numerical Thermal-Flow Simulation and Multistring Stress Analysis. In SPE Thermal Well Integrity and Design Symposium. Society of Petroleum Engineers.

Mainguy, M. \& Innes, R. 2018, "Explaining Sustained" A"-Annulus Pressure in Major North Sea HighPressure/High-Temperature Fields", SPE Drilling \& Completion.

Mohammed, A.I., Oyeneyin, B., Atchison, B. and Njuguna, J., 2019. Casing Structural Integrity and Failure Modes in a Range of Well Types-A Review. Journal of Natural Gas Science and Engineering.

Munson, D.E., 2004, January. MD constitutive model parameters defined for gulf coast salt domes and structures. In Gulf Rocks 2004, the 6th North America Rock Mechanics Symposium (NARMS). American Rock Mechanics Association.

Tang, Y., Wang, G., Li, Z., Chen, S., Du, L. \& LI, W. 2013, "Practice and understanding on multiple crack volume fracturing in open hole horizontal well section of Zone Su53", Oil Drill Prod Technol, vol. 35, pp. 63-67.

Turon, A., Camanho, P.P., Costa, J. and Dávila, C.G., 2006. A damage model for the simulation of delamination in advanced composites under variable-mode loading. Mechanics of materials, 38(11), pp.1072-1089.

Wang, H., Marongiu-Porcu, M. and Economides, M.J., 2016. Poroelastic and poroplastic modeling of hydraulic fracturing in brittle and ductile formations. SPE Production \& Operations, 31(01), pp.4759.

Wang, H., 2015. Numerical modeling of non-planar hydraulic fracture propagation in brittle and ductile rocks using XFEM with cohesive zone method. Journal of Petroleum Science and Engineering, 135, pp.127-140.

Wang, Q., Zhang, L. \& Hu, J. 2018, "Real-time risk assessment of casing-failure incidents in a whole fracturing process", Process Safety and Environmental Protection, vol. 120, pp. 206-214.

Wu, J. and Knauss, M.E., 2006, January. Casing temperature and stress analysis in steam-injection wells. In International Oil \& Gas Conference and Exhibition in China. Society of Petroleum Engineers.

Xi, Y., Li, J., Liu, G., Cha, C. \& Fu, Y. 2018, "Numerical investigation for different casing deformation reasons in Weiyuan-Changning shale gas field during multistage hydraulic fracturing", Journal of Petroleum Science and Engineering, vol. 163, pp. 691-702.

Xi, Y., Li, J., Yu, Y., Li, Z. \& Mei, B. 2017, "Coupling Effect of Transient Temperature-Pressure on Casing String During Volume Fracturing in Shale Gas Wells", Chinese Materials Conference Springer, pp. 985.

Xing, Y.K., Zhang, G.Q., Lin, Q., Bu, X.Q., Da, Y.P. and Qi, Y., 2017, August. Subcritical Fracture Process of Sandstone with AE Energy Analysis. In 51st US Rock Mechanics/Geomechanics Symposium. American Rock Mechanics Association.

Yan, W., Zou, L., Li, H., Deng, J., Ge, H. \& Wang, H. 2017, "Investigation of casing deformation during hydraulic fracturing in high geo-stress shale gas play", Journal of Petroleum Science and Engineering, vol. 150, pp. 22-29.

Yin, F., Han, L., Yang, S., Deng, Y., He, Y. \& Wu, X. 2018, "Casing deformation from fracture slip in hydraulic fracturing", Journal of Petroleum Science and Engineering, vol. 166, pp. 235-241.

Yin, F., Xiao, Y., Han, L. \& Wu, X. 2018, "Quantifying the induced fracture slip and casing deformation in hydraulically fracturing shale gas wells", Journal of Natural Gas Science and Engineering, vol. 60, pp. 103-111. 
Yu, H., Lian, Z. \& Lin, T. 2016, "Study on failure mechanism of casing in stimulated reservoir volume fracturing of shale gas", Journal of Safety Science and Technology, vol. 12, no. 10, pp. 37-43.

Yu, H., Lian, Z., Lin, T. \& Zhu, K. 2016, "Experimental and numerical study on casing wear in a directional well under in situ stress for oil and gas drilling", Journal of Natural Gas Science and Engineering, vol. 35, pp. 986-996.

Zhang, G.M., Liu, H., Zhang, J., Wu, H.A. and Wang, X.X., 2010. Three-dimensional finite element simulation and parametric study for horizontal well hydraulic fracture. Journal of Petroleum Science and Engineering, 72(3-4), pp.310-317.

Zhaowei, C., Lin, S. \& Degui, X. 2017, "Mechanism of casing deformation in the Changninge Weiyuan national shale gas demonstration area and countermeasures". 